

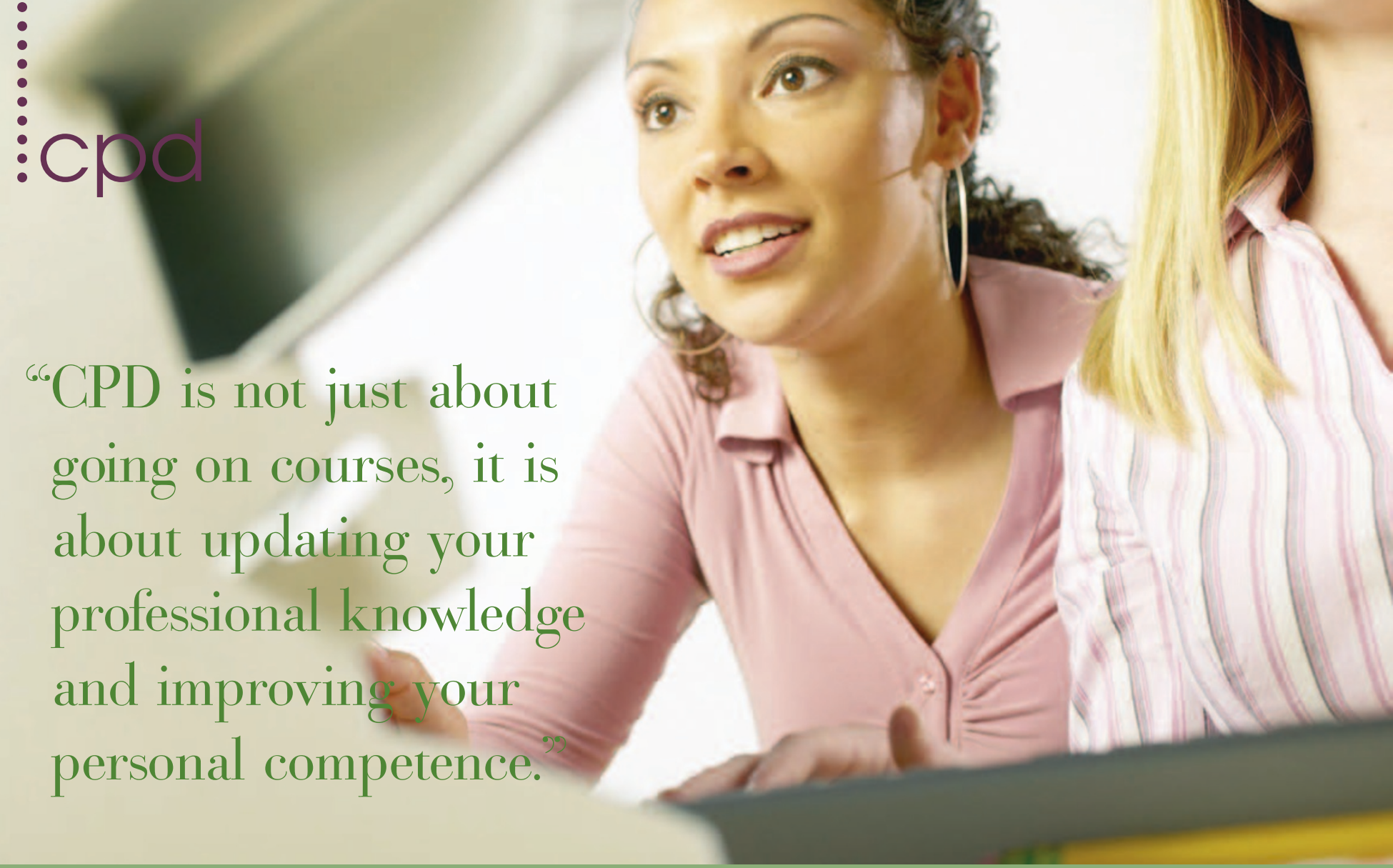

activity against to test whether it is verifiable. ${ }^{1}$

1. You must get a certificate or documentary evidence from the course provider or organiser that you took part in the activity; and it should state how many hours were spent on the activity. Keep this certificate for your CPD file.

2. The activity must have clear educational aims and objectives

3. The activity must have clear expected outcomes

4. The activity must have a feedback mechanism where you have the chance to say what you thought of the activity with a view to improving it if necessary.

If a CPD activity does not meet all of these requirements then you cannot count it towards verifiable CPD hours, but it does not mean that you should not attend or participate. It still counts towards your personal development and can be included as a general CPD activity. Don't forget to record your attendance in your own records though.

Activities that can be counted as general CPD for example are: private study, background research, reading journals (such as Vital), see the box below for more examples.

The GDC is currently consulting on what the best approach to CPD would be for the dental team. It is likely to be based around the model described here. The GDC hopes to improve on the current CPD system for dentists (for example by including some core compulsory subjects by 1 Jan, 2007) and then introduce compulsory CPD for the rest of the registered team from 2008. If you have any comments to make to this consultation or would like to see the full consultation document, visit the GDC website at www.gdc-uk.org and click on 'Revalidation consultation'. But don't delay, the consultation period ends on March 16th.

References

1 Compulsory Continuing Professional Development: what it means for you. General Dental Council

2 CPD and the future http://www.dla.org .uk/issues/education/cpd01.php

\section{CPD Activities}

- Courses and lectures

- Vocational training or general professional training study days

- Educational parts of professional and specialist society meetings

- Peer review and clinical audits

- Distance learning

- Multimedia learning (web-based or CD-ROM)

- Staff training

- Educational workshops at conferences

- Reading journals

- Background research

- Private study amongst others
Some proposed changes to the current system under consultation:

The addition of 4 core subjects which all registrants, including DCPs may have to do verifiable CPD in:

- Cardio-pulmonary resuscitation (CPR);

- Cross-infection control;

- Legal and ethical issues;

- Handling complaints.

A fifth possible subject for dentists only:

- Radiography and radiation protection

\section{Recording CPD}

Always make a note of:

- The date of the activity

- The venue (if applicable)

- The organisation running the activity

- Verifiable or general CPD

- Number of hours spent on the activity 